\title{
Effect of Formula Food Supplementation (MP-ASI) with Local Product on Growth and Development Among Indonesia Infants 6 to 9 Month of Ages
}

\author{
Helmizar ${ }^{\#}$, Fasli Jalal ${ }^{*}$, Nur Indrawati Lipoeto* and Endang L Achadi ${ }^{1}$ \\ \# Department of Nutrition Faculty of Public Health Andalas University of Padang - 25144. Indonesia \\ E-mail:eelbiomed@gmail.com \\ * Department of Nutrition Faculty of Medicine Andalas University of Padang, Indonesia \\ E-mail: faslijalal@yahoo.com; indra.liputo@gmail.com \\ * Department of Nutrition Faculty of Public Health, University of Indonesia \\ E-mail: endang.achadi@gmail.com
}

\begin{abstract}
The purposes of the study were to evaluated the effect formula food supplementation as complementary feeding (MP-ASI) on growth and development of infants 6 to 9 month of ages. This study setting was in Tanah Datar District West Sumatera Province Indonesia and the participants amount were 355 infants aged 6 to 9 months at beginning of the study. This community trial using Cluster Randomized Control Trial (CRCT) was conducted to 40 clusters from 5 selected villages were assessed for baseline data . The children were divided into 4 groups: food supplementation group (FS-group), psychosocial stimulation (PS-group), Food and psychosocial stimulation group (FP+PS-group) and control group (C-group). The intervention group received formula food supplementation (MP-ASI) with local product about 250 to $300 \mathrm{kcal}$ and 6 to 8 gram protein daily for 6 month. The results shows that 271 children completed the study. After 6 month of intervention, for F-Group mean of length is improved $6.61 \mathrm{~cm}+2.11 \mathrm{SD}$ and for FP-Group improved $6.27 \mathrm{~cm}+\mathbf{2 . 2 4} \mathrm{SD}$. The FP-Group benefitted in difference Z-score weight for height of nutritional status at baseline and after 6 month of intervention are FP-groups $(0.57+1.15$ SD) compare the F-groups $(-0.16+1.12$ SD) . There was significant effect of food supplementation and psychosocial stimulation on children's cognitive development, improving $21.37+$ 12.43 SD point and on motoric development improving $20.65+18.38 \mathrm{SD}$ point $(\mathrm{P}<0.001)$. It can be concluded that the formula food supplementation (MP-ASI) combination with psychosocial stimulation had strong effect to the improvement of infants's growth and development.
\end{abstract}

Keywords — Food Supplementation, MP-ASI, Growth and Development, Infants, Indonesia

\section{INTRODUCTION}

As stated in the Lancet Series on Maternal and Child Undernutrition, stunting is still a prominent global issue that causes a major threat to health, growth and development of children worldwide [1]. In Indonesia, the Basic Health National Survey 2013 showed a prevalence of $37 \%$ of stunting in children under five years of age [2]. From conception until two years of age, children grow and develop rapidly [4] and nutritional demands are high. Most of the growth faltering happens in this period of life, and low birth weight contributes to early faltering. Nutritional problems that have been experienced prenatally and during early childhood do not only increase the risk of infant morbidity and mortality, but will also affect long-term growth and development of children [3]. Early life interventions to prevent growth failure and to support optimal growth and development of children are therefore crucially needed [5].

The transferability of such programs from one locality to another is low and programs need to be tailored to the local context. In Indonesia, a few studies on combined nutritional supplementation and psychosocial stimulation in children have been conducted [6],[7]. However, the impact of nutritional supplementation and psychosocial stimulation for growth to the development of children still inconsistent until now. There is no intervention study with nutritional supplementation and psychosocial stimulation based on local culture approach has been conducted for infants in West Sumatera Province. The aim of this study therefore was to design and investigate the effect of formula food 
supplementation and psychosocial stimulation program based on the local culture on growth and development of infants living in Tanah Datar Distric West Sumatra Province, Indonesia.

\section{METHOD}

This research was conducted in two stages, namely: (1) Phase the formative study is the stage of development of formula food supplementation (MP-ASI) and development of psychosocial stimulation Manjujai curriculum and handbook for parents, and field personnel training. (2) Phase intervention implementation and evaluation of the results on the growth and development of infants.

\section{A. Study design and subjecs}

The study was a cluster-randomized controlled trial with a $2 \times 2$ factorial design conducted from January until December 2013. The study was done in Tanah Datar District in West Sumatra Province, Indonesia, where a high prevalence of stunting (36\%) in infants 6 to12 months of age was found by our preliminary study. We chose this location because it forms the centre of the Minangkabau culture in West Sumatra Province. The final selection of the study sites was based on the number of households with low to middle socio economic status, demographic characteristics, as well as accessibility of the area.

We included infants aged 6 to 9 months at the start of the study who were apparently healthy, predominantly breastfed, and did not have symptoms of chronic or severe illnesses, severe clinical malnutrition or congenital abnormality. The infants who were low birth weight or growth faltering still included in this study which more intention in the intervention. The sample size was calculated based on an anticipated increase of length of $6 \mathrm{~cm}$ with an assumed SD of 0.26 with $\alpha=0.05$ (2-sided), $\beta=0.20$, a design effect of 1.5 for cluster randomization, and an anticipated dropout of $10 \%$. We calculated that we would need 81 infants for each intervention group. When taking into account a dropout of $10 \%$, the total sample size for four groups intervention were 356 infants, it was calculated using sample size formula hypothesis testing between two means [8].

\section{B. Selection and randomization}

In Tanah Datar District, 40 sub-villages (Jorong) from five sub-districts were selected and formed the clusters for the study. First, a list with the names and demographics of infants 6 to 9 month of age from all the sub-villages was obtained from the Community Health Center. The list names of infants was further confirmed by community health workers in each sub-village. Each cluster had 6 to 12 eligible infants with a total of 355 in all 40 clusters combined. The sub-villages or Jorong were randomly assigned to one out of four interventions in a $2 \times 2$ factorial design, i.e 1) Food Supplementation group (FS-group); 2) Psychosocial Stimulation group (PS-group); 3) Food Supplementation and Psychosocial Stimulation group (FS+PS-group); and 4) Control group (C-group). Randomisation was done by a researcher using a table random. All infants in a cluster received the same intervention.

\section{Intervention}

All mothers or caregivers of the infants were invited to Community Health Center together with their identification card. They received a full explanation about the purpose of the study as well as of all the study procedures. Weight and length of the infants were assessed and mothers were interviewed for obtaining data on household characteristics, socio-economic status, health status, food intake and lactation habits. Assessment of cognitive, language and motor development were done using the Bayley Scale of Infant Development, Third edition (BSID-III), and the quality of psychosocial stimulation was assessed using the Infant HOME inventory method [9], [10]. After this, infants were enrolled into their assigned intervention groups. After 180 days of intervention, all baseline measurements were repeated.

\section{Formula food supplementation}

The products for food supplementation were developed in collaboration with the Department of Nutrition of Polytechnic Health of the Ministry of Health, Padang. In a pilot study conducted in 2010-2011, a formula food supplement was developed using local food sources (local MP-ASI) and this product was pilot tested on infants and children. This initial MP-ASI was adjusted to the local habits for making infant food in West Sumatra. This resulted in three different formulas that were pre-tested for acceptance by mothers and their infants. These three local formulas contained red sweet potatoes, purple sweet potatoes, red rice, red bean, green bean, soy bean and mujair fish. All these formula foods were mixed with cooking oil, and a litlle sugar and salt. The three complementary foods were similar in protein and calorie content. The three formulas wereused as a slurry with the addition of water, so as to meet the ideal criteria of the WHO in terms of energy density, $\mathrm{pH}$, and viscosity (thickness). Viscosity of the formula was measured using a rotation viscosimeter $\mathrm{RV}$ no. 4 at $50 \mathrm{rpm}\left(40^{\circ} \mathrm{C}\right)$, $\mathrm{pH}$ formula was using Accumet $\mathrm{pH}$-meter. The test of organoleptic have been conducted to choose the three best formula; test of physical properties for kamba density test and water absorption, test laboratory for chemical contain, mineral zinc, iron, calcium contain and microbiology, analysis of nutrient according to recommended nutrient requirements for infants. The nutritional composition analysed using Nutri Survey Programme and list of nutritional composition of local food.

Each packet of the formula was adjusted for age groups (6-8 months, 9-11 months, > 12 months) and provided approximately 200 to $250 \mathrm{kcal}$ of energy and 6 to 8 gram of protein. The nutritional composition of the three formula foods were standardized according to nutrition recommendations for infants in the three age categories. A handbook for mothers or caregivers was made to explain them how to prepare and administer the supplementary food, as well as some other information about complementary feeding of their infants at home.

\section{E. Follow-up measurements}

All infants and their mothers of intervention groups were visited weekly by a trained health worker to monitor and reinforce compliance with the two intervention programs. 
During the visits, mothers/caretakers in the PS and FS+PS groups were stimulated to perform the Manjujai playing with their infant at home. Other family members of the infant were also encouraged to perform Manjujai with the infant as is usually done in the Minangkabau culture. Preparation of the food supplement was monitored in the FS and FS+PS groups, and if needed the preparation method was corrected. Compliance data on the intake of the food supplements and the psychosocial stimulation program were collected monthly on a monitoring form.

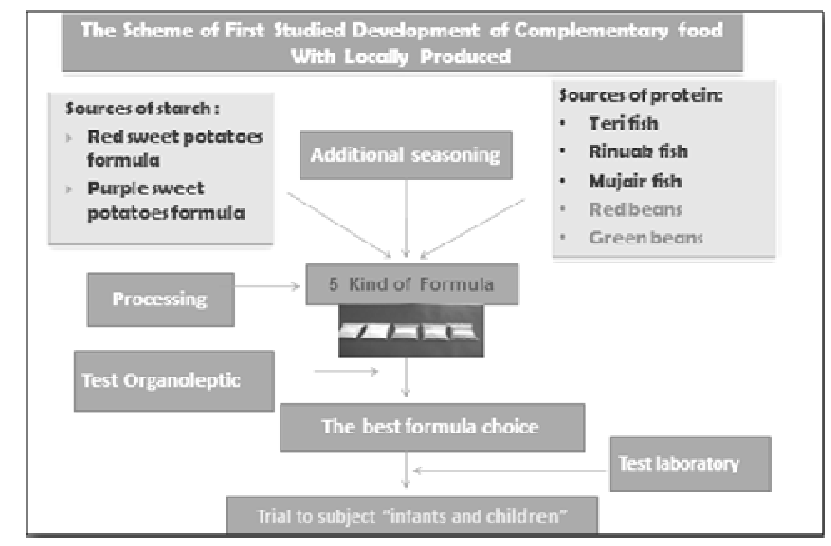

Fig. 1 The scheme of First Studied Development of Complementary food with locally produced

\section{F. Anthropometry}

All anthropometric measurements were performed by trained dietitians using standard techniques as described by Gibson R (12). Anthropometric measurements were taken at baseline (month 0), at mid-point (month 3), and at the end (month 6) of the intervention. For body weight measurement, children were wearing light clothes without shoes, using an electronic scale with a precision of $0.1 \mathrm{~kg}$ (give the brand name). The recumbent length of the children was measured using a length board with a precision of $0.1 \mathrm{~cm}$.

\section{G. Dietary intake}

Dietary intake of infants was assessed by dietitians using 24-hour food recall method for all infants at the baseline and the endline. For this, dietitians visited the infants at home on 1 consecutive day to interview the mother on their infant's dietary intake during the previous 24 hours. Dietary intake from breastfeeding was not measured in this study. All other complementary food given by parents was recorded at the baseline and at the final evaluation.

\section{H. Developmental assessment}

The cognitive, language and motoric development of infants was assessed using the third edition of the Bayley Scale of Infant Development (BSID-III) at baseline and at the end of the study. Two trained psychologists assessed the infants while blinded to the treatment groups. Most infants were tested in a room in the community center athough in some cases the test was conducted at the infants home. All items in the Bayley III instrument were translated to the local Indonesian language and the testing was performed under supervision of a psychologist.

\section{Compliance}

Compliance was recorded in various ways: 1) daily record of field staff who distributed the food supplementation; 2) weighing of the food supplementation left by the end of the weekly period; and 3) observation of the parent practical module of psychosocial stimulation in parenting class. Two research assistants stayed in the study location to organize and monitore the compliance.

\section{J. Ethical Approval}

The study protocol was approved by the Ethical Committee of the Faculty of Medicine at Andalas University, Padang, Indonesia. Each mother received full explanation about the purpose of the study and the study procedures. Both oral and written parental consent was obtained before the start of the trial. Research permits were obtained from the Faculty of Medicine, University of Andalas in Padang, as well as from the District government of Tanah Datar in West Sumatra Province.

\section{K. Statistical Analysis}

The data were analyzed using the SPSS-Win, version 20 (SPSS Inc, Chicago). After data collection, cleaning and coding, data entry was conducted. The children's antropometric indices were calculated according to WHO Athro 2005 software and are expressed as mean + SD of the Z-score for weight-for- age (WAZ), height-for-age (HAZ), and weight-for-height (WHZ). Cognitive, language and motor development scores were expressed as mean + SD. Paired samples t-test was used to compare the groups at baseline in order to confirm the homogeneity within groups in terms of nutritional status and development outcomes, and other possible confounders during the intervention period. Group comparisons (control vs intervention) were perfomed using independent $\mathrm{t}$ test for continuous variables and chisquare test for categorical variables. We compared the characteristics with each groups using One Way ANOVA Test. Cohen's effect size was applied to measure difference of WAZ,HAZ, WHZ and developmental score.

\section{RESULTS AND DISCUSSION}

The result of preliminary study was conducted to find the best formula local MP-ASI by optimal composition of nutritional requirement for infant 6 to 9 month of ages were assigned for intervention. Trial manufacture of formula local MP-ASI will be adjusted with the habit of making infant food in location West Sumatra society. This experiment consists of three kinds of formulas will be tested as a treatment and its acceptance by the mother and child. These three kinds of formula local MP-ASI are: MP-ASIcontaining wheat red sweet potatoes, purple sweet potatoes, teri /rinuak /mujair fish. All of this formula is also mixed with cooking oil and sugar or salt added such that the obtained three-MP formula milk protein iso-and iso-caloric. The three formula was produce a slurry with the addition of water, so as to meet the ideal criteria of the WHO in terms of energy density, $\mathrm{pH}$, and viscosity (thickness) it as shown in the scheme below.

Based on the requirements made of two kinds of formulas Porridge that Formula Sweet Potato, Red Beans and Mujair Fish (F-UKM) and Formula Red Rice, Green Beans and 
Mujair Fish (F-BKM). Selection of the use of these two kinds of formulas aimed at ensuring that the combination of nutrients given for infants so that the nutrients are obtained more varied infants, but it also introduces with a variety of complementary feeding. The result of composition of raw materials, chemical and microbiological test the selected formula food suplementation as shown in Table 1 and Table 2 below.

TABLE I

THE COMPOSITION MATERIALS OF 2 KINDS OF FORMULA FOOD SUPPLEMENTATION

\begin{tabular}{|l|c|c|}
\hline \multirow{2}{*}{ Materials } & \multicolumn{2}{|c|}{ Kind of formula } \\
\cline { 2 - 3 } & F-UKM & F-BKM \\
\hline Red sweet potatoes flour (gr) & 90 & - \\
Red bean flour (gr) & 5 & - \\
Red Rice flour (gr) & - & 30 \\
Green bean flour (gr) & - & 10 \\
Mujair fish flour (gr) & 30 & 30 \\
Sugar (gr) & 8 & 8 \\
Coconut oils (gr) & 10 & 10 \\
\hline
\end{tabular}

TABLE II

RESULTS OF CHEMICAL ANALYSIS AND MICROBIOLOGY OF FORMULA FOOD SUPPLEMENTATION

\begin{tabular}{|l|c|c|}
\hline \multirow{2}{*}{ Materials } & \multicolumn{2}{c|}{ Kind of formula } \\
\cline { 2 - 3 } & F-UKM & F-BKM \\
\hline Water (\%) & 5.84 & 5.52 \\
Ash (\%) & 3.96 & 2.00 \\
Protein (\%) & 24.81 & 32.89 \\
Lemak (\%) & 12.41 & 9.52 \\
Karbohidrat (\%) & 62.78 & 57.59 \\
Energy (calori) & 251.8 & 261.4 \\
Zinc (mg/kg) & 27.45 & 21.01 \\
Calcium (mg/kg) & 11033.14 & 2815.18 \\
iron (mg/kg) & 27.59 & 26.59 \\
Kamba density & 0.74 & 0.74 \\
Viscosity & 40 & 50 \\
Total Microbe & $0.4 \times 10^{4}$ & $1.8 \times 10 .{ }^{4}$ \\
\hline
\end{tabular}

At enrollment, there were no differences in infants characteristics between groups (Table 3). In each groups, the average age of infants was 7,6 month and the proportion of boys was $51.4 \%$ in FS-group compared to the proportion of girls in the amount of $48.6 \%$ at the enrollment. The proportion of infants with exclusive breastfeeding was more in FS-groups or about $60.6 \%$ and the C-group about $39.4 \%$. There were no significantly difference across groups characteristics of subjects at the time of enrollment $(\mathrm{P}>$ $0.05)$.

As shown in Table 4, body weight of the infants increased significantly with $1.3-1.5 \mathrm{~kg}$ over the intervention period in all of the groups, but was not statistically different between groups $(\mathrm{P}=0.197)$. Similarly, length also increased significantly with 5.8-6.9 $\mathrm{cm}$ over the 6-month intervention period in all of the intervention groups, but the increment in length was significantly smaller in the control group $(\mathrm{P}=0.013)$. The change in weight-for-length $\mathrm{z}$-scores improved significantly in the two groups receiving psyschosocial stimulation $(\mathrm{P}<0.05)$, and changes in weight- for-length $\mathrm{z}$-scores over the intervention groups were significantly different between groups $(\mathrm{P}=0.002)$. However, length-for-age $\mathrm{z}$-scores decreased most in the intervention groups and remained unchanged in the control group over the intervention period. Change in length-for-age Z-Scores was significantly different between treatment groups at the end of the study $(\mathrm{P}=0.002)$. Weight-for-age $\mathrm{z}$-scores did not change significantly over time, and changes were not different between groups $(\mathrm{P}>0.05)$.

The Bailey Scales cognitive, motor and language scores increased over the intervention period in all treatment groups (Table 5). Changes in cognitive and motor scores were significantly different between groups, with larger changes in the intervention groups as compared to the control group.

The results of this study are not much different from the results of previous studies with nutritional supplementation interventions in some other developing countries. The study in Jamaica was founded an average increased the length of the child in the group of children stunted by supplementation increased an average of $6.5 \mathrm{~cm}(+1.7)$ and increased average $5.6 \mathrm{~cm}(+1.3)$ in the group of children non supplementation. The results of this study concluded that Jamaica nutritional supplementation can put on weight and height in the first 6 months of intervention, but there are no longer benefit to the speed of growth (catch-up) in stunted children over 2 years of intervention. The results of this study also concluded that the acceleration of linear growth cannot be achieved if the child remains how in a poor neighborhood. Potential growth rate can only be determined after a period of growth in the days of puberty. Longer benefits obtained in children with malnutrition of food supplementation which started in the womb and continues at the beginning of a infant's life [13],[14].

The average Z-Score WHZ, HAZ and WAZ after 6 months of the intervention of the results of this study are still under-NCHS median WHO standards but there is the presence of short-range distances approaching the standard median WHO-NCHS. The decline in the growth of the child based on Z-Score WHZ, HAZ and WAZ has a condition that is often found in developing countries, including Indonesia. According to the WHO report, decrease the Z-Score HAZ and WAZ has been started since the age of two months until the age of 12 months, after the decline began to decrease [17]. According to Victora CG (2010), the results of anthropometric data analysis children from 54 countries compared with the 2006 WHO standards described for the average Z-score of WHZ children from all over the country slightly above the standard at the age of 1-2 months, and decreased to children aged 9 months and increased again approaching the standard until the age of 24 months and may continue above the standard until the age of 48 months and decreased back to the age of 58 months. For the average ZScore WAZ decrease ranging from ages 4 months to 24 months of age and tends to be stable after that. For the average Z-Score HAZ at the early age of the child's life has been under standard and dramatically decreases until the age of 24 months and looks to increase after the age of 24, 36 and 48 months. 
TABLE III

INFANTS CHARACTERISTICS BY GROUP ON ENROLLMENT OF THE STUDY

\begin{tabular}{|l|c|c|c|c|c|}
\hline Characteristics & $\begin{array}{c}\text { FS-group } \\
(\mathrm{n}=72)\end{array}$ & $\begin{array}{c}\text { PS-group } \\
(\mathrm{n}=59)\end{array}$ & $\begin{array}{c}\text { FS+PS-group } \\
(\mathrm{n}=69)\end{array}$ & $\begin{array}{c}\text { C-group } \\
(\mathrm{n}=71)\end{array}$ & P-value \\
\hline Age (mo) & $7,5 \pm 1,18$ & $7,6 \pm 1,12$ & $7,6 \pm 1,25$ & $7,9 \pm 1,26$ & 0,650 \\
Gender (\%) & & & & 59,2 & \\
boys & 51,4 & 47,5 & 59,4 & 40,8 & \\
girls & 48,6 & 52,5 & 40,6 & 3,772 \\
Birth weight (kg) & $3,15 \pm 0,42$ & $3,06 \pm 0,42$ & $3,13 \pm 0,44$ & $3,03 \pm 0,40$ & 0,393 \\
Birth length (cm) & $49,26 \pm 2,50$ & $47,55 \pm 3,30$ & $47,90 \pm 3,55$ & $47,93 \pm 4,80$ & 0,191 \\
Birth order & $2,29 \pm 1,40$ & $2,39 \pm 1,50$ & $2,26 \pm 1,33$ & $2,06 \pm 1,10$ & 0,579 \\
Excusive Breastfeeding (\%) & 43,1 & 57,6 & 55,1 & 39,4 & 0,096 \\
\hline
\end{tabular}

*Data are reported as mean and SD, and compared with One Way ANOVA test

${ }^{+}$Data are reported as $\%$ and compared with the ${ }_{x}^{2}$ test

Abbrevariations: FS-group = Food Supplementation-group; PS-group = Psycosocial Stimulation-group; FS+FP-group = both Food Supplementation and Psychosocial Stimulation-group; C-group = Control-group

\section{Treatment effects}

TABLE IV

ANTHROPOMETRIC INDEXES OF THE CHILDREN AT ENROLLMENT AND 6 MO LATER *

\begin{tabular}{|c|c|c|c|c|c|}
\hline Growth/Nutritional Status & $\begin{array}{l}\text { FS-group } \\
(\mathrm{n}=72)\end{array}$ & $\begin{array}{l}\text { PS-group } \\
(\mathrm{n}=59)\end{array}$ & $\begin{array}{c}\text { FS+PS-group } \\
(n=69)\end{array}$ & $\begin{array}{c}\text { C-group } \\
(\mathrm{n}=71)\end{array}$ & P-value \\
\hline \multicolumn{6}{|l|}{ Weight (kg) } \\
\hline Enrollment & $7,64 \pm 0,84$ & $7,55 \pm 0,93$ & $7,52 \pm 0,85$ & $7,52 \pm 0,90$ & 0,853 \\
\hline $6 \mathrm{mo}$ & $8,92 \pm 1,04$ & $8,89 \pm 0,94$ & $9,03 \pm 0,86$ & $8,77 \pm 0,84$ & 0,850 \\
\hline Change $(\Delta)$ & $1,28 \pm 0,76^{1}$ & $1,33 \pm 0,07^{1}$ & $1,50 \pm 0,73^{1}$ & $1,43 \pm 0,76^{1}$ & 0,197 \\
\hline \multicolumn{6}{|l|}{ Length $(\mathrm{cm})$} \\
\hline Enrollment & $67,51 \pm 2,45$ & $67,98 \pm 2,90$ & $68,44 \pm 2,97$ & $67,72 \pm 2,59$ & 0,219 \\
\hline $6 \mathrm{mo}$ & $74,38+2,64$ & $74,22+2,77$ & $74,10+2,27$ & $73,52+2,11$ & 0,673 \\
\hline Change $(\Delta)$ & $6,86 \pm 2,08^{1}$ & $6,24 \pm 2,30^{1}$ & $6,66 \pm 2,41^{1}$ & $5,8 \overline{1} \pm 2,50^{1}$ & $0,013^{2}$ \\
\hline \multicolumn{6}{|l|}{ Weight for length $\mathrm{z}$ score/WHZ } \\
\hline Enrollment & $-0,21 \pm 0,99$ & $-0,61 \pm 0,98$ & $-0,74 \pm 1,09$ & $-0,42 \pm 0,92$ & 0,449 \\
\hline $6 \mathrm{mo}$ & $-0,37 \pm 1,07$ & $-0,31 \pm 0,94$ & $-0,17 \pm 0,81$ & $-0,41 \pm 0,91$ & $0,011^{2}$ \\
\hline Change $(\Delta)$ & $-0,16 \pm 1,12$ & $0,30 \pm 0,88^{1}$ & $0,57 \pm \overline{1}, 15^{1}$ & $0,00 \pm 0,93$ & $0,001^{2}$ \\
\hline \multicolumn{6}{|l|}{ Length for age $\mathrm{z}$ score/HAZ } \\
\hline Enrollment & $-0,61 \pm 1,01$ & $-0,36 \pm 1,25$ & $-0,24 \pm 1,15$ & $-0,78 \pm 1,05$ & 0,281 \\
\hline $6 \mathrm{mo}$ & $-0,86 \pm 1,04$ & $-0,89 \pm 0,92$ & $-1,11 \pm 0,93$ & $-0,80 \pm 0,81$ & $0,021^{2}$ \\
\hline Change $(\Delta)$ & $-0,24 \pm \overline{0}, 88^{1}$ & $0,53 \pm 1,17^{1}$ & $-0,87 \pm \overline{1}, 12^{1}$ & $-0,01 \pm \overline{0}, 86^{1}$ & $0,002^{2}$ \\
\hline \multicolumn{6}{|l|}{ Weight for age $\mathrm{z}$ score/WAZ } \\
\hline Enrollment & $-0,55 \pm 0,83$ & $-0,71 \pm 0,93$ & $-0,73 \pm 0,99$ & $-0,79 \pm 0,93$ & 0,636 \\
\hline $6 \mathrm{mo}$ & $-0,68 \pm 1,01$ & $-0,65 \pm 0,88$ & $-0,62 \pm 0,78$ & $-0,80 \pm 0,81$ & 0,468 \\
\hline Change $(\Delta)$ & $-0,12 \pm 0,78$ & $0,06 \pm \overline{0}, 76$ & $0,11 \pm \overline{0}, 88$ & $0,01 \pm 0,86$ & 0,368 \\
\hline
\end{tabular}

All values are mean \pm SD value for Z-score from National Center for Health Statistics reference data

${ }^{1}$ Significantly difference before and 6 mo later within groups, $\mathrm{P}<0,05$ (Paired t-Test)

${ }^{2}$ Significantly difference at 6 mo later from each groups, $\mathrm{P}<0,01$ (One way ANOVA test)

Abbrevariations: FS-group = Food Supplementation-group; PS-group = Psycosocial Stimulation-group; FS+FP-group $=$ both Food

Supplementation and Psychosocial Stimulation-group; C-group = Control-group

TABLE V

BAYLEY SCORES OF ALL GROUPS AN BASELINE AND FINAL TEST SESSION*

\begin{tabular}{|l|c|c|c|c|c|}
\hline Developments & $\begin{array}{c}\text { FS-group } \\
(\mathrm{n}=72)\end{array}$ & $\begin{array}{c}\text { PS-group } \\
(\mathrm{n}=59)\end{array}$ & $\begin{array}{c}\text { FS+PS-group } \\
(\mathrm{n}=69)\end{array}$ & $\begin{array}{c}\text { C-group } \\
(\mathrm{n}=71)\end{array}$ & P-value \\
\hline Cognitive Score & & & & & \\
$\quad$ Enrollment & $100,49 \pm 8,10$ & $100,34 \pm 8,50$ & $97,68 \pm 11,19$ & $98,03 \pm 10,97$ & 0.205 \\
6 mo & $116,53 \pm 11,67$ & $119,24 \pm 10,28$ & $119,06 \pm 9,52$ & $113,24 \pm 10.79$ & 0,003 \\
Change $(\Delta)$ & $16,04 \pm 10,54^{1}$ & $18,89 \pm 12,59^{1}$ & $21,37 \pm 12,24^{1 \mathrm{a}}$ & $15,30 \pm 12,56^{1}$ & $0,014^{2}$ \\
\hline Language Score & & & & & \\
$\quad$ Enrollment & $97,53 \pm 10,51$ & $99,41 \pm 11,67$ & $95,61 \pm 10,50$ & $98,45 \pm 12,45$ & 0,233 \\
6 mo & $108,51 \pm 12.95$ & $111,78 \pm 11.21$ & $108,29 \pm 11.02$ & $108,28 \pm 11.02$ & 0.280 \\
Change $(\Delta)$ & $11,01 \pm 12,71^{1}$ & $12,37 \pm 14,14^{1}$ & $12,68 \pm 13,97^{1}$ & $11,42 \pm 13,66^{1}$ & 0,591 \\
\hline
\end{tabular}




\begin{tabular}{|l|c|c|c|c|c|}
\hline Motoric Score & & & & \\
Enrollment & $95,33 \pm 12,58$ & $95,33 \pm 12,58$ & $91,00 \pm 16,08$ & $98,20 \pm 17,52$ & 0.811 \\
6 mo & $111,03 \pm 14.74$ & $111,80 \pm 14.32$ & $111,65 \pm 13.94$ & $109,79 \pm 10.77$ & 0.012 \\
Change $(\Delta)$ & $16,47 \pm 16,41^{1}$ & $15,77 \pm 16,75^{1}$ & $20,65 \pm 18,38^{1}$ a & $11,59 \pm 15,82^{1}$ & $0,005^{2}$ \\
\hline
\end{tabular}

*All values are $x \pm$ SD assessed by The Bayley Scale Infant Development Thirth Edition (2006)

${ }^{1}$ Significantly difference before and 6 mo later within groups, $\mathrm{P}<0,05$ (Wilcoxon Sing Ranks Test)

${ }^{2}$ Significantly difference at 6 mo later from each groups $\mathrm{P}<0,01$ (Kruskal Wallis Test)

Abbrevariations: FS-group = Food Supplementation-group; PS-group = Psycosocial Stimulation-group; FS+FP-group = both Food

Supplementation and Psychosocial Stimulation-group; C-group = Control-group

In this study, food supplementation MP-ASI give effect being to increase the length of the infants but little effect on weight gain. Still not achieve optimal growth of infants in this study, among others, can be caused by the intake of nutrients, especially energy intake $(61.20 \%)$ and protein $(70.19 \%)$ infants were still lower than the nutritional adequacy should be. In addition, infants in these complementary feeding group had experienced diarrhea with an average length of duration of 5.11 days (range 2-14 days). A history of disease infections experienced by children causes of nutritional supplementation given can not be used by the body to achieve optimal growth, but this nutritional supplementation is needed to meet the nutritional needs of children after recovery from illness.

\section{CONCLUSIONS}

The potential local food source can be to produce for complementary feeding with optimal nutrient contain for optimal infant's growth and the infants who get food supplementation additional intake of nutrients, especially energy and protein so that infants become more active and able to carry out activities related with the better of motoric development.

\section{ACKNOWLEDGMENT}

This study is partly funded by Indonesian Danone Institude Foundation. The views expressed herein are those of the individual authors, and do not necessarily reflect those of Indonesian Danone Institude Foundation. We also thanks to Ministry of Education Indonesia, Government Tanah Datar district, Supervisors (Risatianti Kolopaking, Rina Hasniati, Susmiati), interviewers, and the community health workers for assistance.

\section{REFERENCES}

[1] Black RE AL, Bhutta, Caufield LE, de Onis M, Wzzati M, et al. Maternal and child undernutrition: Global and regional exposures and health consequences. . The Lancet 2008. p. 243-60.

[2] Ministry Of Health I. The Basic Health Research Indonesia 2013. Jakarta: Minisry of Health Indonesia; 2013.

[3] Martorell R, Bernardo L H, linda S A, Aryeh D S, Linda. Weigh Gain in first two years of life is an important predictor of schooling outcomes in pooled analyses from five birth cohorts from low and middle income countries. The Journal of Nutrition. 2009; Vol 109.
[4] Dewey KG, Begum K. Long-term consequences of stunting in early life Maternal and Child Nutrition. 2011.

[5] Victora CG, Onis Md, Pedro Curi Hallal et al. Worldwide Timing of Growth Faltering: Revisiting Implications for Interventions. Pediatrics. 2010;125 (3):e.473-80.

[6] Herawati N, Hardinsyah, Khomsan A, et al. Effects of Fortified Supplement, Nutrition Education and Stimulation on Growth and Development of 6-12 months infants. Pacific Early Childhood Research Association; Singapura: PECERA; 2012.

[7] Yuliana. Effect of Nutritional Education and Psychososial Stimulation on Growth and Developmment of Preschool Children Indonesia. Bogor: Bogor Institute of Agriculture; 2007.

[8] Lemeshow S, Lwanga SK. Sample size determinant in health studies. Jeneva: World Health Organization; 1991.

[9] Bettye M. Caldwell and Bradley RH. Home Observation For Measurement Of The Environment. Little Rock, Arkansas: University of Arkansas at Lilltle Rock; 1984.

[10] Bayley N. Bayley Scales of Infants Development Third Edition. New York: The Psychological Corperation; 2006.

[11] Fahmida U. Multi-Micronutrient Supplementation for Infant Growth and Development and the Contributing Role of Psychosocial Care. Dissertation Post Graduate Program. Jakarta: University Indonesia.; 2003.

[12] Gibson SR. Principle of Nutritional Assessment. New York: Oxford University Press; 2009.

[13] Walker SP, Powell CA, McGregor SM G, Himes JH, Chang SM. Nutritional supplementation, psychosocial stimulation, and growth of stunted children: the Jamaican study. Am J Clin Nur. 1991.

[14] Walker SP, Chang SM, Powell CA, McGregor S. Effect of psychosocial stimulation and early supplementation in early childhood on psychosocial functioning in late adolescence: follow-up of randomized controlled trial.BMJ, doi:10.1136.2005.

[15] Nahar B. Effects of food supplementation and psychosocial stimulation on growth and development of severy malnourished children; Intervention studies in Bangladesh. Sweden: Uppsala University; 2012.

[16] Pollit E PS, Jahari A, et al. Effect of an energy and micronutrient supplement and mental development and behavior under natural condition in undernourished children in Indonesia. European of Clinical Journal of Nutrition 2000;54(Suppl 2):S80-S90.

[17] Mora J, Herrera M, Super C. Long-term effects of food supplementation dan psychosocial intervention on the psysical growth of Colombian infants at risk of malnutrition. Child Dev. 1990;61 (1):29-49.

[18] McGregor SG, Schofield W, Powell C. Development of severe malnourished children who receive psychosocial stimulation six-year follow up. Pediatrics 79. 1987.

[19] Eagle PL, Menon P, Haddad L. Care and Nutrition concept and Maesurement. International Food policy Research Institute. 1997.

[20] Wachs TD, Georgieff M, Cusick S, McEwen BS. Issues in the timing of integrated early intervention: contribution from nutrition, neuroscince, and psychological research. AnnN YAcadSci. 2014;1308 89-106. 